\title{
BALANÇO HIDRICO EM CULTURA DE CANA-DE-AÇÚCAR EM FUNÇÃO DE TRÊS ESPAÇAMENTOS DE PLANTIO
}

\author{
RONALDO LAZARI RUFINO
}

Orientador: KLAUS REICHARDT

Dissertação apresentada à Escola Superior de Agricultura "Luiz de Queiroz", da Universidade de São Paulo, para obtenção do título de Mestre em Agronomia, na área de Solos e Nutrição de Plantas.

PIRACICABA

Estado de São Paulo - Brasil Junho, 1982 
A minha esposa Marize,

Aos meus filhos Ronan e Thais,

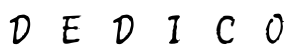




\section{AGRADECIMENTOS}

Ao concluir o presente trabalho, o autor expressa os seus agra decimentos às seguintes pessoas e instituições:

- Ao Professor Dr. KZaus Reichardt, pela orientação,participação e amizade oferecida durante o decorrer do curso;

- Ao Professor Dr. Paulo Leonel Libardi, pelas sugestões, cola boração e amizade proporcionada;

- Ao Engenheiro Agrônomo Bernardo Yasuhiro Ide, pela inestimävel colaboração prestada na realização deste trabalho;

- Á Direcão do Centro de Tecnologia da Copersucar, pelo apoio material e oportunidade oferecida;

- Á FINEP (Einanciadora de Estudos e Projetos), pelo apoio financeiro ao projeto realizado entre FINEP-DFM-COPERSUCAR.

- Á Empresa Brasizeira de Pesquisa Agropecuária (EMBRAPA), pela concessão da bolsa de estudos.

- Ao Instituto Agronômico do Paraná (IAPAR), pela oportunidade oferecida para a realização deste curso;

- E a todos que, direta ou indiretamente, contribuíram para a realização deste trabalho. 
Página

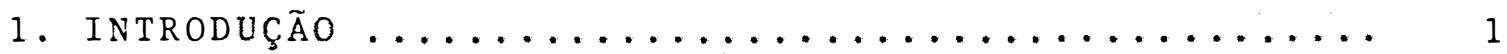

2. REVISÃo de literatura $\ldots \ldots \ldots \ldots \ldots \ldots \ldots \ldots \ldots \ldots \ldots$

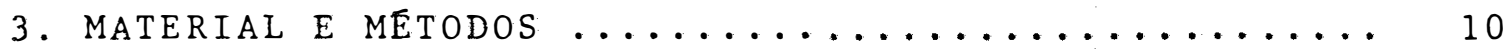

3.1. Caracterização geral do experimento ......... 10

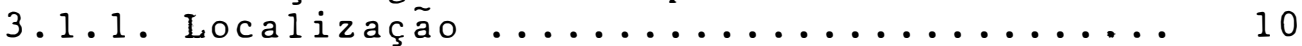

3.1.2. Características climáticas da Região ........ 10

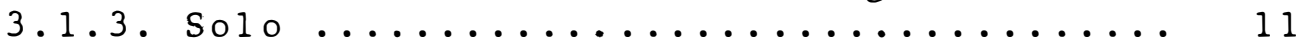

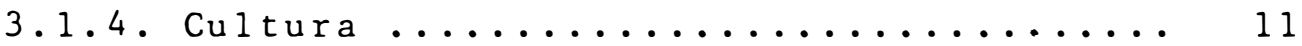

3.1.5. Espaçamento da cultura e práticas cul-

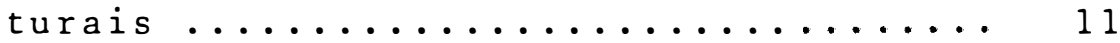

3.1.6. Avaliação da massa verde (t/ha) ...... 12

3.2. Medidas tomadas para determinação do balanço

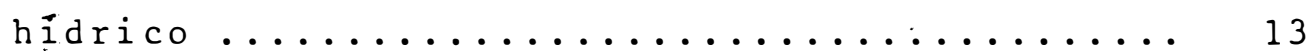

3.2.1. Variação do armazenamento da água no

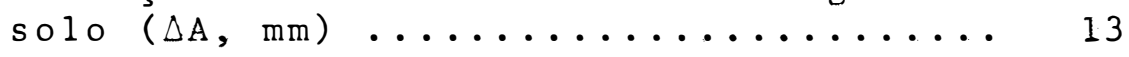

3.3. Precipitação pluvial $(P, \mathrm{~mm}) \ldots \ldots \ldots \ldots \ldots$

3.4. Deflūvio superficial (R, mm) ............ 16

3.5. Evapotranspiração real ou atual (Et $\left.{ }_{r}, \mathrm{~mm}\right) \ldots 16$

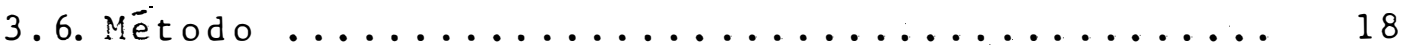

3.6.1. Fundamentos do método do balanço hídri

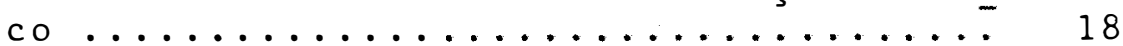

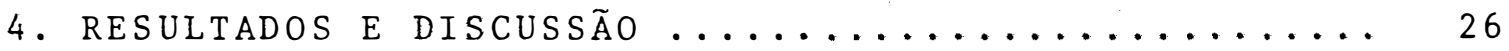

4.1. Variáveis da equação do balanço hỉdrico ...... 26

4.1.1. Armazenamento e suas variações no tempo. 26

4.1.2. Fluxo no limite inferior do Elemento de

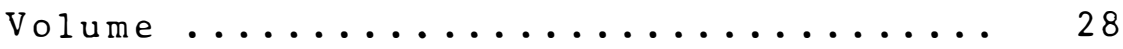

4.1.3. Evaporação, evapotranspiração de referéncia ou atual e evapotranspiração real ou atual ..... 29

4.1.4. Precipitação, armazenamento de água e produção de massa verde ............. 30

4.1.5. Produção de massa verde em relação à evapotranspiração atual ou real .......

5. conclusões ........................... 41

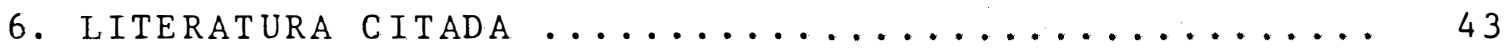




\section{BALANÇO HIDRICO EM CULTURA DE CANA-DE-AÇOCAR}

SOB TRES ESPAÇAMENTOS DE PLANTIO

Ronaldo Lazari Rufino

Klaus Reichardt

Orientador

\section{RESUMO}

o presente trabalho teve como objetivo o estudo do balanço hídrico em uma cultura de cana-de-açūcar, variedade SP 70-1143, sob três espaçamentos de plantio $\quad(1,10 \mathrm{~m}$; $1,40 \mathrm{~m}$ e $1,70 \mathrm{~m})$. O experimento foi conduzido em um Latossol Ro xo, na Estação Experimental do Centro de Tecnologia da Copersucar no município de Piracicaba.

O armazenamento da àgua no perfil de solo foi estimado até $80 \mathrm{~cm}$ de profundidade, utilizando tensiômetros e curva característica de retenção de àgua, determinada em labo ratório com amostra de solo com estrutura indeformada. A evapotranspiração foi estimada por meio de tanque de evaporação 
CLASSE A e a drenagem obtida como incognita da equação de balanço hỉdrico.

As perdas por drenagem para o primeiro ciclo da cultura foram $34,1 \%(1,10 \mathrm{~m}), 36,4 \%(1,40 \mathrm{~m})$ e $44,2 \%(1,70 \mathrm{~m})$ em relação a evapotranspiração e para o segundo ciclo $55,5 \%$ $(1,10 \mathrm{~m}), 55,6(1,40 \mathrm{~m})$ e $55,5(1,70 \mathrm{~m})$. 


\section{WATER BALANCE IN SUGAR CANE CROP \\ UNDER THREE SPACINGS}

Ronaldo Lazari Rufino

Klaus Reichardt

Adviser

\section{SUMMARY}

The present study had the objective of better understanding soil-plant-water relationships of sugar-cane crops planted in three different spacings $(1.10 \mathrm{~m}, 1.40 \mathrm{~m}$ and $1.70 \mathrm{~m}$ between rows). The experiment was conducted on a Latossol Roxo site located in Piracicaba, Brazil, using the sugar-cane variety SP 70-1143.

The methodology applied included the establishment of the water balance. Soil water storages were estimated from tensiometer data, using soil-water retention curves obtained in the laboratory with undisturbed soil samples. Evapotranspiration was estimated from Class A pan evaporation and deep drainage was left as an unknown in the water balance. 
Data show little effect of spacing on water

balance but the spacing of $1.40 \mathrm{~m}$ showed the greatest vegetative growth. During the period studied, drainage losses were $34.1 \%$ $(1.10 \mathrm{~m}) ; 36.4 \%(1.40 \mathrm{~m}$ and $44.2(1.70 \mathrm{~m})$ of evapotranspiration during the drier period, and $55.5 \%(1.10 \mathrm{~m}) ; 55.6 \%(1.40 \mathrm{~m})$ and $55.5 \%(1.70 \mathrm{~m})$ for the wet period. 


\section{INTRODUÇÃO}

o solo é um meio dinâmico que responde aos estímulos, oriundos tanto da ação dos agentes naturais como daqueles induzidos pelo homem. Assim no que se refere à àgua, as interações do sistema solo - planta - atmosfera, interferem nos processos ativos do armazenamento da água no solo, da eva potranspiração, do deflūvio superficial, da drenagem profunda, entre outros mais.

A necessidade hidrica constitui-se em fator primordial à realização dos processos fisiológicos da planta que por sua vez determinam os sucessos e fracasos da produção. O conhecimento do ciclo hidrológico e as relações soloágua - planta se fazem necessárias para determinar sistemas de manejo que levem a níveis satisfatórios de produtividade.

O objetivo deste trabalho baseia-se na hipótese de que o espaçamento de plantio de cana-de-açúcar afetaria 
as relações solo-ägua-planta, influenciando o consumo de água, a distribuição radicular e, consequentemente, a nutrição da cultura, o desenvolvimento da planta e, em ūltima instāncia, a produtividade. 0 conhecimento sobre esses problemas trariam subsídios na avaliação das práticas tradicionais adotadas na exploração canavieira, permitindo sugerir modificações que le vem a um conjunto nas relações solo-água-planta que determine a otimização da produtividade.

No trabalho em apreço, empregou-se a metodologia do balanço de água com o intuito de estudar a influência de diferentes espaçamentos de plantio de uma variedade de ca na-de-açūcar sobre as relações solo-água-planta. 
2. REVISÃO DE LITERATURA

Para o entendimento pormenorizado da utilização da água por uma cultura qualquer, se faz necessário a de terminação do balanço hídrico, representante da contabiliza ção das entradas e saídas da água do sistema solo-planta-atmosfera.

A bibliografia a esse respeito é vasta, sendo citado diversos procedimentos para a estimativados parâmetros componentes da equação de balanço, dependendo do interesse apresentada pelos diversos ramos da ciência agronômica.

A metodologia empregada na determinação do ba lanço hídrico, que utiliza um volume conhecido de solo, tem sido aplicado por diversos autores e, entre eles, podemos ci tar ROSE e STERN (1967) que apresentam uma análise da taxa de absorção da água para diversas profundidades da cultura, além 
de outros, como Holmes et a $i$ i (1967) BLACK et a $i$ i

$(1969)$

BARRADA (1971) e, em nosso meio CRUCIANI (1972), REICHARDT et alii (1974), LUCHIARI JUNIOR (1978), CASTRO (1979), PAIVA JUNIOR (1980), BRUNINI et alii (1981).

Os componentes da equação do balanço hỉdrico, precipitação, deflúvio superficial ou "runoff", evapotranspiração e variação do armazenamento, são mensuráveis por diver sas alternativas. O componente precipitação pode ser quantificado diretamente pela utilização de pluviômetros ou pluvió grafos (HANDBOOK OF METEOROLOGICAL INSTRUMENTS; LONDON;1956). o volume da água de irrigação pode ser controlado por meio de hidrômetro. Na quantificação desse componente, desde que se utilizem técnicas corretas, o erro varia de 1 a 5\%, segundo DOWNEY (1972). O escoamento superficial ou "runoff", quando presente, é um componente que exige, para sua determinação, a adoção de metodologia característica (IAPAR, 1977). CRUCIANI (1972), em trabalho com cana-de-açūcar (Saccharum sp.), estimou o deflúvio superficial valendo-se da intensidade de precí pitação obtida por pluviógrafo e da taxa de infiltração do so lo estudado, pelo infiltrômetro de MUNTZ modificado. STERRS et alii (1973) consideraram nulo o deflúvio superficial quan do os locais de estudo fossem planos e assim também PEREIRA et alii (1974) relatam ser desprezível quando a declividade do solo fosse inferior a $3 \%$. REICHARDT (1975) relata que a de terminação do deflúvio superficial é complexa tanto pela ne- 
cessidade de técnicas apropriadas, como também por envolver grande volume de ägua.

A drenagem profunda constitui-se num dos compo nentes do balanço hỉdrico mais complexo de ser estimado, sendo comumente desprezado ou englobado como parte do armazenamento de água no solo ou da evapotranspiração. A quantificação da drenagem profunda tem sido medida ou estimada de forma indireta ou determinada como incógnita do balanço (ROSE, 1966). A drenagem profunda quando não considerada, infere erros crassos na estimativa da evapotranspiração (NIXON et alii, $1960)$.

A utilização da equação de Darcy na determinaçäo da drenagem profunda, possibilitou a elaboração de inúmeros trabalhos. Procedendo assim, BLACK et alii (1969) determinaram a variação do armazenamento, propondo um gradiente hidráulico unitário e drenagem de água na mesma razão, para todas as profundidades de um solo homogêneo. GEISEL et a $i$ i (1970) pro põem a distinção para perdas por drenagem profunda e evapotranspiração, pela determinação de um plano de fluxo zero no perfil do solo. DAYAN e VACHAUd (1972) comprovaram essa técni ca, salientando a importância da determinação direta da drena gem profunda.

Em nosso meio, REICHARDT et arii (1974), valen do-se da proposição de GEISEL et alii (1970), estimaram a dre 
nagem profunda, salientando que esta não pode ser negligencia da sem justificativa plausivel, principalmente para solos de regiãotropical, onde pode corresponder a mais de $30 \%$ do balanço. PEREIRA et alii (1974), desenvolvendo trabalho em solo cultivado com café, relataram que a drenagem profunda corres pondeu a $10 \%$ no período de crescimento e $40 \%$ no período de ma turação e colheita. LUCHIARI JUNIOR (1978) encontrou valores correspondentes a $10 \%$ de perda por drenagem, em Terra Roxa E truturada, durante o ciclo da cultura do feijão (Phaseolus vulgaris L.). SINGER e RUSSEL (1979) abordam que para uso consuntivo das culturas, $\vec{e}$ aconselhável analisar os perfis de (umidade versus profundidade) para melhor entender as implica ções sobre a percolação e a drenagem interna, que também atuam na precisão dos dados do balanço hỉdrico.

A evapotranspiração requer uma série de proce dimentos para sua interpretação, pois envolve os processos de evaporação do solo e transpiração por meio de plantas que, con juntamente, compõem a evapotranspiração. A dieterminação deste componente, segundo TANNER (1968) pode ser efetuada por três métodos básicos: aquele das variáveis micrometeorológicas, pe lo método do balanço hidrológico e por meio de métodos empirí cos que necessitam correções em função dos anteriores.

A estimativa da evapotranspiração pela equação do balanço hídrico apresenta precisão relativa, pois depende 
dos procedimentos envolvidos na análise das variáveis dos ou tros componentes tais como: nível de umidade, precipitação, e vaporação do solo nu e capacidade de armazenamento do solo ( LINCH e EDWARDS, 1980). TAMES (1962) afirma a importância do estudo de demanda da. àgua às culturas, em diferentes tipos de solo, considerando a profundidade do solo a ser atingida pelo sistema radicular das plantas. MILlAR et alii (1977), ao pes quisarem a evapotranspiração relacionada com o potencial da água no meio poroso, propuseram uma análise das variáveis envolvidas na dinâmica da àgua no solo.

A água envolvida durante o ciclo hidrológico das culturas pode ser quantificada com a aplicação dos métodos diretos, utilizando-se plantas e equipamentos no solo (BLACK et alii, 1969). A combinação de métodos empíricos e a equação do balanço hidrológico na determinação da evapotranspiração potencial, faz-se por diversos modos, conforme o ins trumental empregado, dentre os quais, incluem-se os evaporimetros representados pelos tanques de evaporação "Classe A", GCI 3000 e YONG'SCREAN PAN, caracterizados por modelos e dimensões particulares, segundo a Tecnical Note no 83 da WORLD METEO ROLOGICAL ORGANIZATION. A utilização de tanques de evaporação na estimativa da evapotranspiração de uma cultura tem sido ob jeto dos mais variados estudos, segundo o modelo de tanque empregado e local de suas determinações, apresentando imensa variação de valores dos coeficientes corretivos de tanque. Na 
estimativa de evapotranspiração real de uma cultura os valores da evapotranspiração potencial são corrigidos e denomina dos de coeficientes de cultura(HARGREAVES, 19.74). Esses coefi cientes são afetados por diversas outras variáveis como carac. terísticas inerentes à própria cultura, época de semeadura, ta xa de crescimento da cultura, duração da estação de crescimen to, condições climáticas e frequência de chuvas (Doorembos e PRUITT, 1975 ).

CRUCIANI (1972), valendo-se de um volume de so 10 e do tanque "Classe A", determinou o balanço hídrico para a cultura da cana-de-açúcar, considerando três estágios vege tativos da cultura, obtendo valores de 0,42;0,76 e 0,79 para os coeficientes de cultura nos respectivos estágios. LUCHIARI JUNIOR (1978), pelo mesmo procedimento de CRUCIANI (1972), obteve o coeficiente 0,88 para cultura de feijão.

o armazenamento de àgua no solo é definido como o total de água retido no interior de seu perfil de profun didade $z$, em dado instante $t$. Fazendo a integração dos perfis de umidade do solo, quantifica-se o armazenamento da ägua. A obtenção dos valores de umidade correspondentes a cada horizonte de um perfil de solo faz-se pelo método gravimétrico, ou pelo emprego da sonda de neutrons (STAMERS et a $i i i$, 1973; BAR ROS FERRAZ, 1968 ; CRUCIANI, 1972 ; REICHARDT, 1974), ou também indiretamente, pela utilização de tensiômetros que, a partir 
de curvas de retenção de água, revelam os perfis consecutivos de umidade do solo $\theta\left(\mathrm{cm}^{3} \cdot \mathrm{cm}^{3}\right)$, correspondente a cada profun didade, os quais, uma vez integrados, fornecem o armazenamento de água no solo (CASTRo, 1979). 
3. MATERIAL E METODOS

3.1. Caracterização geral do experimento

3.1.1. Localização

o experimento do presente trabalho foi conduzi do em ärea experimental, denominada de talhão 48, da Fazenda Santo Antônio, ou sede física do Centro de Tecnologia da Copersucar, no município de Piracicaba, Estado de São Paulo, apresentando as seguintes coordenadas geográficas:

$$
\begin{aligned}
& \text { LATITUDE: } 22^{\circ} 42^{\prime} \mathrm{S} \\
& \text { LONGITUDE: } 477^{\circ} 38^{\prime} \mathrm{W}
\end{aligned}
$$

3.1.2. Características Climáticas da Região

Pela classificação de WILHEIM e KOEPPEN determi na-se que o clima é do tipo sub-tropical com inverno seco (Owa), citado por LEITE (1978) e apresentando, segundo dados do Departamento de Física e Meteorologia da ESALQ: 
Precipitação média anual: $1247 \mathrm{~mm}$

Temperatura média anual: $20,8^{\circ} \mathrm{C}$

Umidade relativa média anual: $69,0 \%$

3.1 .3 .5010

Segundo levantamento realizado por DEMATTE (1971), com a finalidade de mapeamento, o solo da área estuda da foi classificado no grande grupo Latossol Roxo, porém com a característica de B textural, denominado Latossol Roxo, com horizonte B textural incipiente, apresentando profundidade su perior a 3 metros, com boa drenagem.

3.1.4. Cultura

A cultura utilizada neste experimento foi a ca na-de-açūcar (Saccharum officinarum, L.), variedade SP 70-1143, que se revela ser pouco exigente em relação a outras variedades, como a SP-1284 e IAC 52-150 (Figura 1) quanto à demanda hídrica, enquanto que a SP 1284 é tida como mais exigente. Da dos levantados pela COPERSUCAR (1982) revelam grande expansão dessa variedade nos ültimos dois anos.

3.1.5. Espaçamento da cultura e práticas culturais

Os espaçamentos adotados entre as linhas de plantio foram: $1,10 \mathrm{~m} ; 1,40 \mathrm{~m}$ e $1,70 \mathrm{~m}$. Antecedendo o plantio 
efetuaram-se os trabalhos normais de aração, gradeação e, pos teriormente, o sulcamento da ärea. Após esta operação, mediuse o comprimento dos sulcos componentes das respectivas parce las (FIGURA 1 e TABELA 1 ).

A cultura foi adubada na ocasião doplantio (em 04 de fevereiro de 1981), com fórmula 5-25-25 de N-P-K-, na do sagem de 70 gramas por metro de sulco para os respectivos espaçamentos.

Na data de 10 de agosto de 1981 , efetuou-se o corte da parte aérea da cultura, danificada em consequência de uma geada ocorrida em 21 de julho de 1981, com temperatura de relva de $1,6^{\circ} \mathrm{C}$.

3.1.6. Avaliação da massa verde ( $t / h a)$

o crescimento foi determinado através de 7 amostragens por parcela, contando-se o nümero de colmos em 10 metros e pesando-se 30 canas inteiras tomadas seguidamente. Deste modo, a avaliação de pêso por hectare foi estimada em função de metros lineares contidos em cada unidade deárea, empregando a fórmula (COPERSUCAR)

$$
\text { TMVH }=\frac{P \cdot N}{K}
$$

onde: 
TMVH = tonelada de massa verde em 1 hectare;

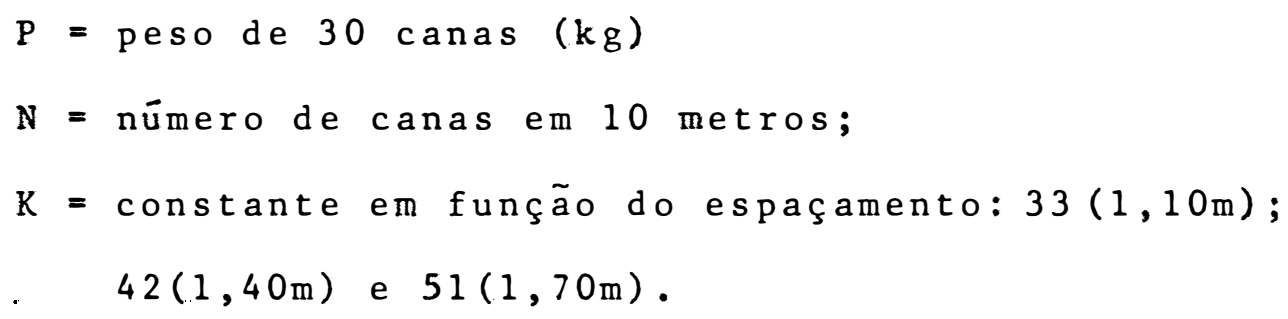

As amostragens foram realizadas em intervalos de aproximadamente 30 dias, sendo que as contagens de nümero de canas foram sempre realizadas em 10 metros previamente mar cados .

3.2. Medidas tomadas para determinação do balanço hỉdrico

3.2.1. Variação do armazenamento da água no solo $(\Delta \mathrm{A}, \mathrm{mm})$

A variação do armazenamento foi estimada a partir de perfis de umidade do solo $\theta\left(\mathrm{cm}^{3} \cdot \mathrm{cm}^{-3}\right)$, obtidos indiretamente através de leituras de tensiômetros e curvas de retenção de água para as profundidades estudadas.

\subsubsection{Tensiômetros}

Foram instaladas duas baterias de 4 tensiômetros providos de manometros, para cada tratamento (FIGURA 1). Após a instalação, os tensiômetros foram completados com água e fluxados, eliminando-se assimar residual do siste ma de manômetro. As operações de fluxagem foram efetuadas a 
cada 7 dias. As leituras das respectivas tensões foram tomadas a intervalos de 48 horas, às 10 horas de cada dia, durante o periodo de 04 de maio de 1981 a 29 de janeiro de 1982 .

0 potencial total $\left(\psi_{t}\right)$ e matricial $\left(\psi_{m}\right)$, às profundidades de $20,40,60$ e $80 \mathrm{~cm}$, foram calculados a partir de médias de leituras utilizando-se as seguintes expressões:

$$
\begin{aligned}
& \psi_{\mathrm{m}}=-12,6 \mathrm{H}_{\mathrm{z}}+\mathrm{h}_{\mathrm{c}}+\mathrm{z}\left(\mathrm{cm} \mathrm{H_{2 }} \mathrm{O}\right) \\
& \psi_{\mathrm{h}}=-12,6 \mathrm{H}_{\mathrm{z}}+\mathrm{h}_{\mathrm{c}}\left(\mathrm{cm} \cdot \mathrm{H}_{2} \mathrm{O}\right)
\end{aligned}
$$

onde: $\mathrm{H}_{2}=$ leitura do tensiómetro ( $\mathrm{cm}$ de $\mathrm{Hg}$ ), instalado à pro fundidade $z$;

$h_{c}=a l t u r a$ do nível de mercūrio na cuba em relação à superfície do solo;

$z=$ profundidade de instalação da cápsula.

3.2.1.2. Curva característica de umidade do solo

Pelo conhecimento da curva característica de umidade de um solo pode-se estimar o potencial matricial $\left(\psi_{m}\right)$, conhecido $\theta\left(\mathrm{cm}^{3} \cdot \mathrm{cm}^{-3}\right)$ e vice-versa. Para cada amostra de um solo homogêneo, o potencial matricial ( $\left.\psi_{m}\right)$ apresenta um valor característico em cadateor deägua $\theta\left(\mathrm{cm}^{3} \cdot \mathrm{cm}^{-3}\right)($ des prezando a histerese). Assim procedendo determinou-se 4 curvas caracteristicas de umidade, para as profundidades de $20,40,60$ 
e $80 \mathrm{~cm}$, respectivas as dos tensiomêtros, sendo que as referentes as três últimas profundidades apresentaram-se coincidentes conforme estão representadas pela (FIGURA 2). As amos tras do solo, foram coletadas com estrutura indeformada, de uma trincheira da própria área experimental (FIGURA I).

A umidade $\theta\left(\mathrm{cm}^{3} \cdot \mathrm{cm}^{-3}\right)$ respectiva a cada poten cial matricial ( $\left.\Psi_{m}\right)$ foi calculada, segundo a expressão:

$$
\theta=\frac{m_{u}-m_{s}}{m_{s}} \cdot d_{g}
$$

onde: $\theta=$ umidade volumétrica $\left(\mathrm{cm}^{3} \cdot \mathrm{cm}^{-3}\right)$;

$$
\begin{aligned}
\mathrm{m}_{\mathrm{u}}= & \mathrm{massa} \text { úmida }(\mathrm{g}) ; \\
\mathrm{m}_{\mathrm{s}}= & \text { massa seca }(\mathrm{g}) ; \\
\mathrm{d}_{\mathrm{g}}= & \text { densidade global }\left(\mathrm{g} / \mathrm{cm}^{3} \text { de solo }\right), \text { que foi determina } \\
& \text { da com amostras de estrutura natural. }
\end{aligned}
$$

$$
\begin{aligned}
& \text { 3.2.1.3. Armazenamento_(A, mm) } \\
& \text { O armazenamento até a profundidade }(\mathrm{L}=80 \mathrm{~cm}) \text {, } \\
& \text { em um instante }\left(t_{i}\right) \text { foi determinado como procederam CASTRO } \\
& \text { (1979) e AMARO e CAVALCANTI (1981), pela expressão abaixo: } \\
& A\left(L, t_{i}\right)=\int_{0}^{L} \theta\left(z, t_{i}\right) d z=\bar{\theta} x I
\end{aligned}
$$

onde: $\bar{\theta}=$ umidade média do perfil ( 0 a $\mathrm{L}$ cm);

$L=$ profundidade do perfil (cm). 
3.3. Precipitação Pluvial $(P, m m)$

Os dados relativos a precipitação pluvial, evaporação de tanque "Classe A", umidade relativa do ar e velocidade máxima e mínima do vento, foram obtidas do Posto Me teorológico da Estação Experimental da Copersucar, instalado, em área anexa às parcelas experimentais (FIGURA l).

\subsection{Deflūvio Superficial (R, mm)}

o deflúvio superficial não foi computado no presente trabalho, tendo em vista a declividade minima da $\vec{a}-$ rea experimental. No campo, durante chuvas intensas, verificou-se certo escorrimento, porém, em pequenas proporções que não se estenderam para fora das parcelas experimentais. PEREI RA et alii (1974) consideraram desprezível este componente, de vido às características do solo e da declividade da ärea ser inferior a $3 \%$.

3.5. Evapotranspiração real ou atual (Et $\left.{ }_{\mathrm{r}}, \mathrm{mm}\right)$

Segundo os procedimentos de DOOREMBOS e PRUNTT (1975) e VILLA NOVA et alii (1977), os valores de coeficiente de tanque "Classe A" e de cultura $\left(K_{c}\right)$, foram estimados com base nas variāveis; $i$ - tamanho da bordadura (100 m), umidade relativa minima do ar $(40$ e $70 \%$ ) e velocidade do vento (2m/ $\left.\mathrm{s}^{\prime}\right)$ para Kp; ii - umidade relativa mínima do ar, velocidade do vento e estádio de desenvolvimento da cultura, para a esti 
mativa de $\mathrm{K}_{\mathrm{c}}$.

A evapotranspiração de referência ou potencial (Eto) foi obtida efetuando-se o produto do valor médio de evaporação de tanque "Classe A", de cada intervalo do balanço hỉdrico, pelo fator de correção $\left(K_{p}\right)$, assim efetuado (Eto $\overline{E C A}$ $x \mathrm{kp}$ ) TABELA 2. Para a estimativa da evapotranspiração real (Etr) foram utilizados os coeficientes de cultura (Kc) multiplicados pelos respectivos valores de Eto (Etr = Eto $x$ Kc), também para cada intervalo em que foram procedidas as leituras (TABELA 2).

No presente trabalho, calculou-se o balanço hi drico, em treze intervalos, sendo os cinco primeiros correspondente ao primeiro ciclo, entre 19 de maio de 1981 a 15 de julho de 1981, e o segundo ciclo composto por oito intervalos de leituras e determinações, considerado de 9 de outubro de 1981 a 29 de janeiro de 1982.

O período de 15 de julho a 9 de outubro de 1981, caracterizou-se por uma estiagem e em consequência deste fato não foram estimados os componentes da equação do balanço hídrico, motivado pelo emprego exclusivo de tensiómetros na determinação dos teores de água no solo e para a esti mativa do armazenamento. Assim sendo os cinco primeiros inter valos e os demais do segundo ciclo foram considerados como es tádios iniciais da cultura. 
3.6. Método

3.6.1. Fundamentos do método do balanço hídrico

o balanço hídrico de um solo cultivado, ou de uma cultura qualquer, refere-se à contabilidade da àgua, ou seja, de suas entradas e saídas, num dado volume de solo, de limitado pela superfície e pelo plano logo abaixo do sistema radicular da cultura, durante um intervalo de tempo. o balan ço hỉdrico é a propria lei da conservação das massas e intima mente ligado ao balanço de energia (REICHARDT, 1975).

Nestas condições, a equação que descreve o ba lanço hídrico de um solo cultivado, de espessura $z$, durante um intervalo de tempo $\Delta t=t_{2}-t_{1}$, estabelece que a soma a gébrica das quantidades que entram (+) e que saem (-) do volu me considerado, é sempre igual à variação da quantidade de água nele armazenada no mesmo intervalo de tempo, podendo ser representada:

$$
\int_{t_{1}}^{t_{2}}\left(p+i-e \pm q_{L}-r\right) d t=\iint_{0}^{L} t_{1}^{t_{2}} \frac{d \theta}{d t} d t d z
$$

que pode ser desdobrada em:

$\int_{t_{1}}^{t_{2}} p d t+\int_{t_{1}}^{t_{2}} i d t-\int_{t_{1}}^{t_{2}} e d t \pm \int_{1}^{t_{2}} q_{L} d t-\int_{1}^{t_{2}} r d t=\int_{0}^{t_{1}} t_{1}^{t}-d t d z$ 
sendo: $p=$ Intensidade de precipitação $\left(m m \cdot\right.$ dia $\left.^{-1}\right)$;

$i=$ Intensidade de irrigação (mm.dia $\left.{ }^{-1}\right)$;

e = Intensidade de evapotranspiração (mm.dia ${ }^{-1}$ );

$\mathrm{q}_{\mathrm{L}}=$ densidade de fluxo de água no solo em $z=\mathrm{L}$ (mm. di $a^{-1}$ );

$r=$ Intensidade de escoamento ou deflúvio superficial $\left(\mathrm{mm} \cdot \mathrm{dia} \mathrm{a}^{-1}\right)$;

$\theta=$ umidade do solo medida em $\mathrm{cm}^{3} \mathrm{H}_{2} \mathrm{O}$ por $\mathrm{cm}^{3}$ de solo. Analisando-se os termos da equação (2), tem-se

no primeiro termo:

$$
\int_{t_{1}}^{t_{2}} p d t=p
$$

refere-se ao total de precipitação pluvial que atinge a super ficie do solo $(z=0)$, no intervalo de tempo $\left(t_{2}-t_{1}\right)$, dado em mm de água. 0 segundo termo representa a quantidade de água de irrigação, como segue:

$$
\int_{t_{1}}^{t_{2}} i d t=I(\mathrm{~mm})
$$

0 terceiro termo refere-se à quantidade de āgua perdida pela evaporação do solo e transpiração das plantas, que quando jun tas, representam a evapotranspiração em $z=0$ :

$$
\int_{t_{1}}^{t_{2}} \text { edt }=-E(\mathrm{~mm})
$$


O quarto termo,

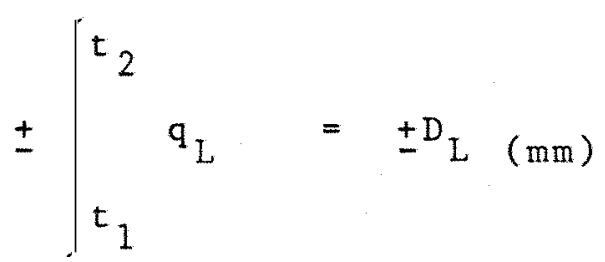

representa a quantidade de água que entra (+) ou que sai (-) no limite inferior do volume do solo em $(z=L)$, que é denomí nado de percolação ou drenagem profunda quando descendente (negativo) e ascensão capilar quando ascendente (positivo). Este com ponente é o mais complexo de ser estimado em um balanço hỉdri co, podendo ser calculado pela equação de Darcy, a qual é re presentada como segue:

$$
q_{I}=-K(\theta) \frac{\partial \Psi}{\partial z}
$$

onde $K(\theta)$ representa a condutividade hidráulica do solo na profundidade ( $L$ ), como função da umidade do solo ( $\theta$ ). Indica a propriedade do solo em transmitir água; $\partial \Psi / \partial z$ representa o gradiente do potencial total ( $\Psi_{t}$ ) da água no solo, na profun didade $(z=L)$, que a força responsável pelo movimento de àgua.

o quinto termo da equação (2) diz respeito à fração da quantidade total de āgua precipitada que atinge a superfície do solo em $(z=0)$ e não é infiltrada, sendo escoa da superficialmente. Essa fração representa uma perda e, conforme a intensidade, provoca o processo erosivo do solo. Esse 
parâmetro também é conhecido por deflūvio superficial ou "runoff" (R) e está na dependência da capacidade de armazena mento de água do solo, como da intensidade e quantidade de chuva, da declividade do local, bem como da cobertura vegetal:

$$
-\int_{t_{1}}^{t_{2}} r d t=-R(m)
$$

o segundo membro da equação (2) do balanço hí drico:

$$
\pm\left(\begin{array}{l}
L^{t} \\
0
\end{array} \int_{1}^{t_{2}} \frac{d \theta}{d t} d t d z= \pm \Delta A \quad(m m)\right.
$$

indica a variação do armazenamento da água no solo, dependente do ganho ou da perda da quantidade de àgua (em $\mathrm{mm}$ ), integrada no perfil do solo (de 0 a $z$ ) no intervalo de tempo $\left(t_{2}-t_{1}\right)$.

A variação do armazenamento da agua pode, portanto, apresentar-se positiva ou negativa, uma vez que sua ra zão depende da magnitude dos termos do primeiro membro da equação (2), que representa o balanço hỉdrico sendo que, pela lei da conservação das massas, a soma algëbrica de todos os componentes da equação deverá ser nula, como se về na equação:

$$
P+I-E \pm D-R \pm \Delta A=0 \quad \ldots \ldots \ldots \ldots
$$


Comumente, tem sido realizado o balanço hidrico conforme realizaram BLACK et alii(1970) e REICHARDT et alii (1974), tendo na equação (3) a evapotranspiração real como in cógnita e quantificados os valores da drenagem profunda através da equação de DARCY (1856).

No trabalho em questão, os valores de evapotranspiração real foram obtidos a partir da evaporação de tan que "Classe A" e permanecendo como incógnita a componente dre nagem. (Fluxo no limite inferior do elemento de volume). 
$\mathrm{N} \uparrow$
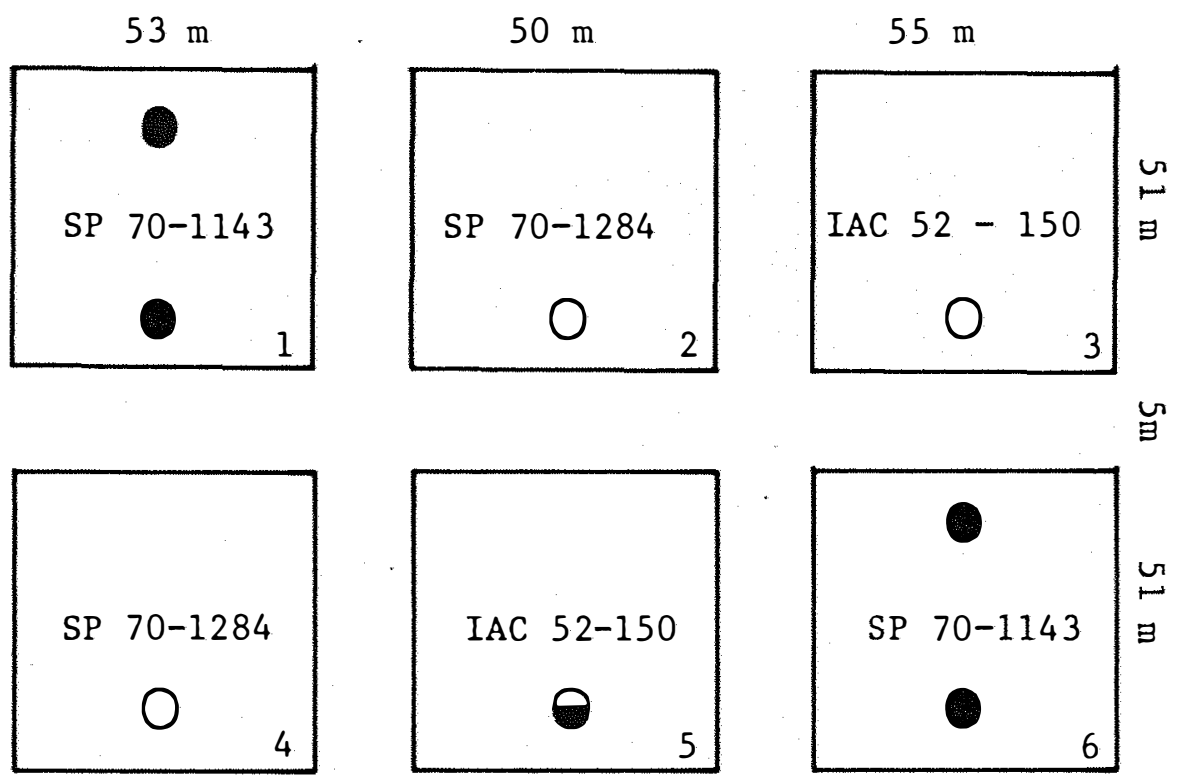

$\exists$
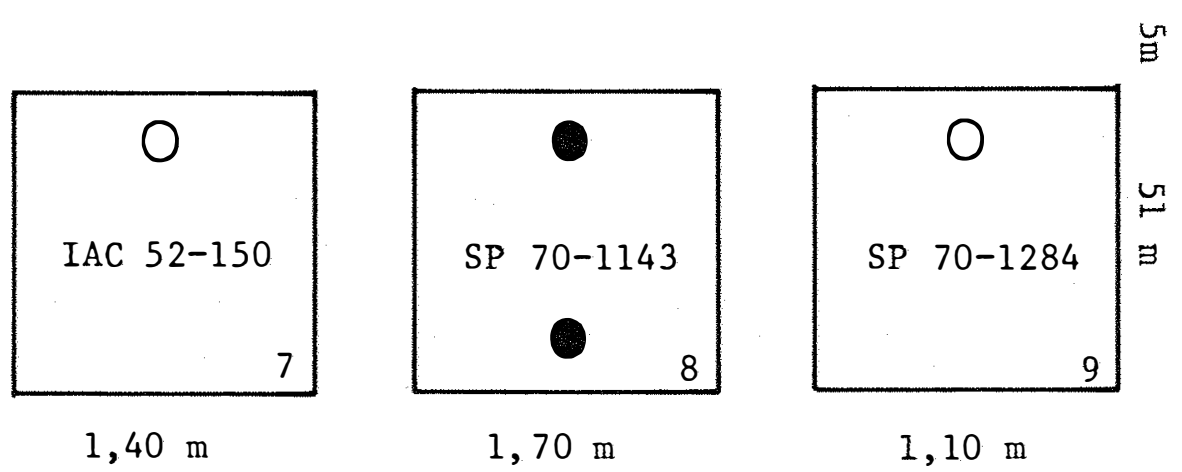

FIGURA 1 - Distribuição das parcelas experimentais com respectivas variedades e espaçamento (m).

- bateria de tensiômetros instalados a $20,40,60$ e $80 \mathrm{~cm}$ de profundidade (parcelas 1, 6 e 8)

tensiômetros instalados a 40,100 e $120 \mathrm{~cm}$ de profundidade (parcela 5)

tensiômetros a $40 \mathrm{~cm}$ de profundidade (parcelas $2,3,4,5,7,9$ )

$\triangle$ posto meteorolögico 


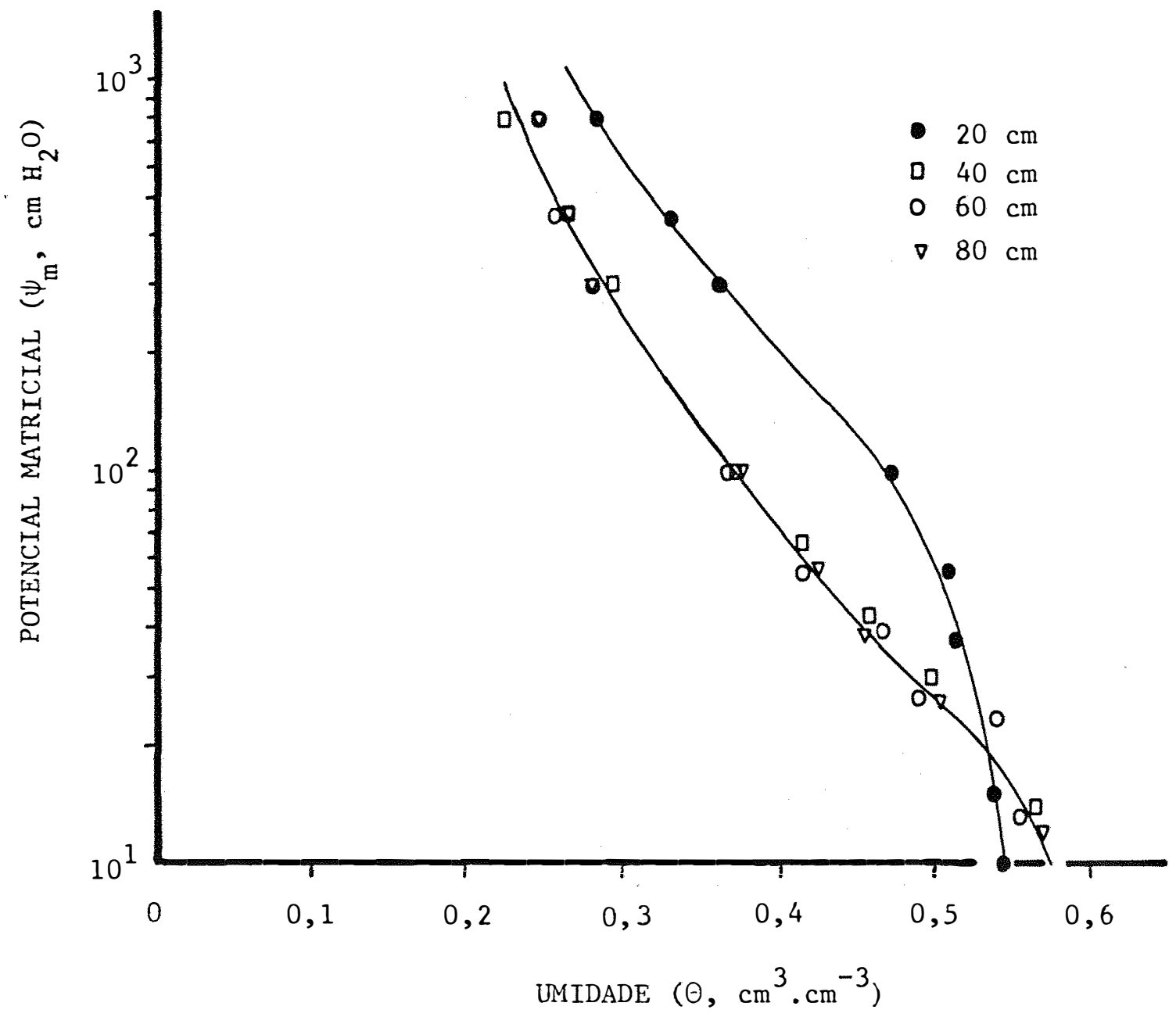

FIGURA 2 - Curva representativa da retenção de água do solo estudado. 


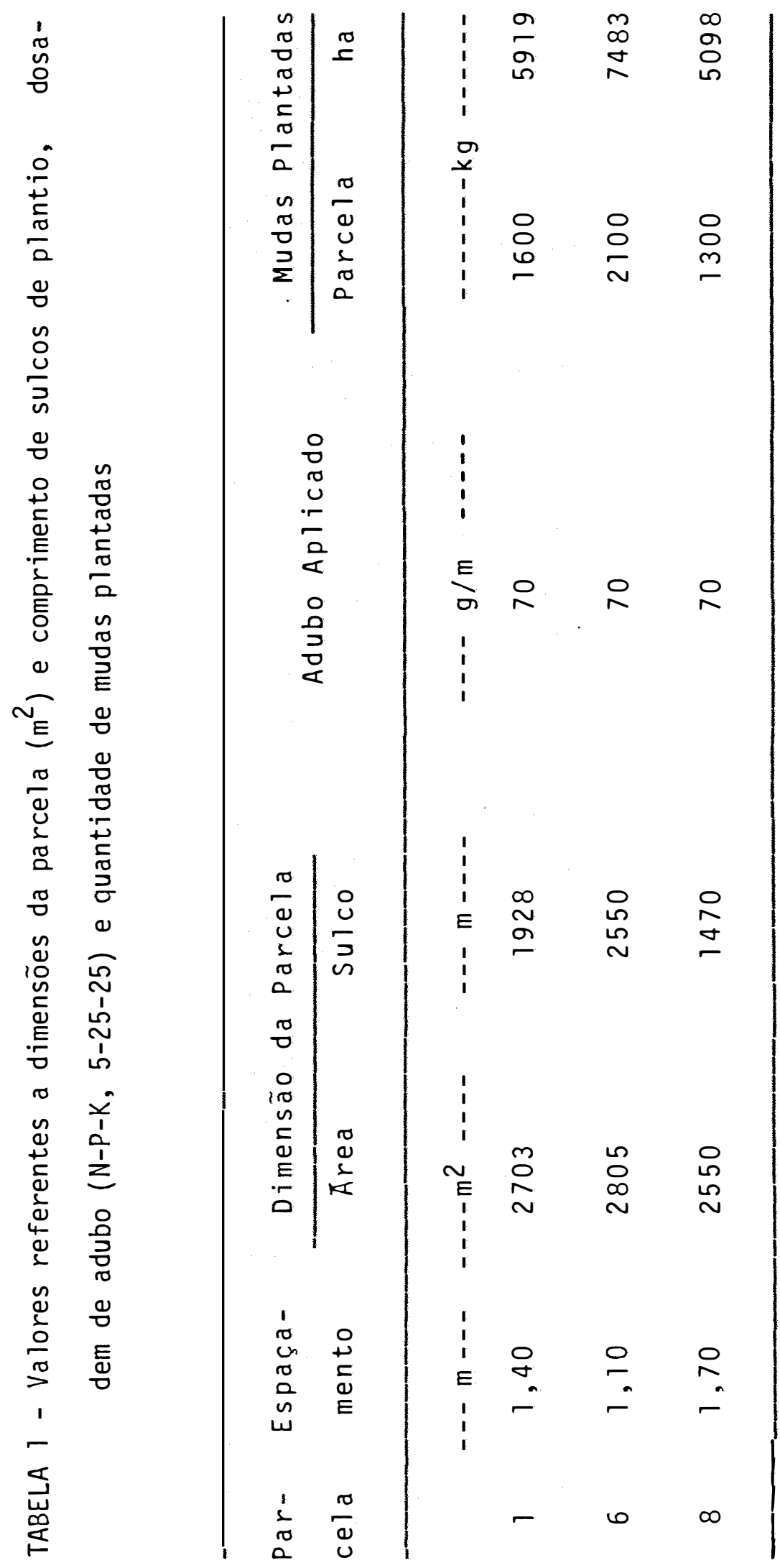




\section{RESULTADOS E DISCUSSÃO}

4.1. Variāveis da equação e balanço hídrico

4.1.1. Armazenamento e suas variações no tempo

Os valores de lâminas armazenadas em função do

tempo e do espaçamento (Figuras 5.1 a e 5.1b), mostram que no período de 19 de maio a 15 de julho de 1981 , ou seja, período caracterizado por deficîencia de precipitação $(111,8 \mathrm{~mm})$, as maiores quantidades de ägua armazenadas no solo referentes ao 19 ciclo da cultura, correspondeu ao espaçamento de $1,70 \mathrm{~m}$ e a menor para o espaçamento referente a $1,40 \mathrm{~m}$ entre 1 inhas de plantio (Figura 5.1a). Efetivamente, como a população de plan tas obedeceu à ordem de $1,10 \mathrm{~m}>1,40 \mathrm{~m}>1,70 \mathrm{~m}$, o conteúdo de água armazenada deveria atender à ordem inversa, ou seja, quanto maior o nümero de plantas, maior o consumo de ägua e menor lâmina armazenada no solo, o que realmente não se veri- 
ficou, apresentando a seguinte sequência: $1,70 \mathrm{~m}>1,10 \mathrm{~m}>$ $1,40 \mathrm{~m}$.

o armazenamento relativo ao primeiro intervalo (09 a 21 de outubro de 1981) do segundo ciclo (Figura 5.1b), mostra que a quantidade de àgua armazenada foi inicialmente superior nos espaçamentos de $1,40 \mathrm{~m}$ e inferior paraode $1,10 \mathrm{~m}$, como demonstra a própria figura e que a partir de 20 de novem bro, os espaçamentos obedeceram à ordem realmente esperada, ou seja, quanto maior o nümero de plantas e conteúdo de água no solo, maior deve ser o consumo pelas culturas, apresentando a sequência de àgua armazenada de $1,70 \mathrm{~m}>1,40 \mathrm{~m}>1,10 \mathrm{~m}$, como observado por MATHERNE (1971). A principal diferença entre as ordens do armazenamento de ägua para cada espaçamento deve ser atribuída ao sistema radicular da cultura, para o período de outubro de 1981 a janeiro de 1982 (segundo ciclo), possivelmente mais ativo que durante o período de maio a julho (primeiro ciclo). Justifica-se assim, durante o intervalo ci tado, o comportamento lógico com a população de plantas por unidade de ärea em cada um dos três espaçamentos. Estas infor mações estão coerentes com as de Tang e Ho, citadas por PARANHOS $(1972)$.

As variações de armazenamento de água pertinen tes a cada espaçamento para o primeiro ciclo (01 de maio a 15 de julbo de 1981) e segundo ciclo (09 de outubro de 1981 a 29 
de janeiro de 1982), revelaram que no primeiro ciclo apenas a leitura referente ao periodo de 30 de maio a 15 de junho (Tabela 3 e Figura 5.1a) apresentou maior conteúdo de água entre duas leituras consecutivas de potencial matricial, revelando consequentemente variações positivas da lâmina de àgua armaze nada no solo, para os três espaçamentos estudados. Outrossim, para o segundo ciclo, as variações exibem mais frequentemente valores positivos dessa variável (Tabela 3), além de demons trar que a variação do armazenamento apresentou-se positiva no final desse ciclo em consequência de maiores precipitações ocorridas.

4.1.2 Fluxo no Limite Inferior do Elemento de Volume

o fluxo interno foi estimado a $80 \mathrm{~cm}$ de profun didade como base a expressão $D=P-E \pm \Delta A$, onde $D=$ (f luxo no limite inferior do elemento volume) permaneceu como incógnita da expressão acima, enquanto que os demais componentes foram determinados conforme procedimento no item 3.6. A metodologia utilizada difere daquelas aplicadas por REICHARDT et a ii (1979) e BRUNINI (1981), que determinaram a drenagem profunda além da zona radicular, utilizando valores de gradiente de po tencial total e da condutividade hidráulica a diferentes con teúdos de umidade de solo e intervalos de tempo.

Na Tabela 3 estão contidas lâminas (mm de 
água) representativas do componente fluxo interno, revelando para o primeiro ciclo da cultura, perdas de: 34,0 para $1,10 \mathrm{~m} ; 36,4 \%$ para $1,40 \mathrm{~m}$ e $44,2 \%$ para $1,70 \mathrm{~m}$, em relação a evapotranspiração.

Os valores do segundo ciclo da cultura, obtidos de 09 de outubro de 1981 a 29 de janeiro de 1982, intervalo de elevada precipitação, nota-se a menor variabilidade quanto aos porcentuais de àgua perdida além do limite de $80 \mathrm{~cm}$, na seguinte ordem de valores em relação a evapotranspiração (E): $55,5 \%(1,10 \mathrm{~m}), 55,6 \%(1,40 \mathrm{~m})$ e $55,5 \%(1,70 \mathrm{~m})$, que efetivamente não demonstrou diferença entre os espaçamentos.

4.1.3. Evaporação, evapotranspiração de referência ou atual e evapotranspiração real ou atual

Os dados de evaporação de tanque "Classe A" (ECA), evapotranspiração potencial, Et ${ }_{o}\left(E C A x_{p}\right)$ e evapotranspiração real ou atual, $E_{r}\left(E t_{o} x_{c}\right)$, estão representados na Tabela 2. Por estes dados, vê-se que a precipitação de 10 de maio a 15 de julho de 1981 equivale aproximadamente a $48 \%$ da evaporação de tanque, $60 \%$ da evapotranspiração poten cial ou de referência e a evapotranspiração real corresponde a $84 \%$ do total precipitado. Caso se considere como perda apenas a Et ${ }_{r}$, haveria naquele estágio $17,15 \mathrm{~mm}$ de água em excesso. Para o segundo ciclo no período de 09 de outubro de 1981 a 29 de janeiro de 1982, observa-se que ECA $(608,96 \mathrm{~mm})$ foi bem in 
ferior à precipitação, enquanto que a Eto e Et ${ }_{\text {, }}$ por sua vez, corresponderam a $53,5 \%(487,17 \mathrm{~mm})$ e $43,50 \%(395,67 \mathrm{~mm})$, respec tivamente. A principal diferença entre esses valores nos dois ciclos da cultura é devida, fundamentalmente, às precipitações entre as duas condições da cultura indicada na Figura 3 , mostrando inclusive a evapotranspiração potencial ou real.

0 coeficiente de cultura $\left(\mathrm{K}_{\mathrm{c}}\right)$ relativos a intervalos que variam de 9 a 18 dias, foram estimados indiretamente, efetuando-se algumas correções das variáveis climáticas, umidade relativa mínima do ar e velocidade do vento, como propuseram DOOREMBOS e PRUITT (1975) e VILLA NOVA et alii $(1977)$.

Os dados da Tabela 2 indicam que a demanda de ägua pela cultura é crescente, conforme revelam os valores de $K_{C}$ para os diferentes períodos, mostrados também na Figura 4. Pela tendência dos valores, nota-se a incoerência da utilização de um valor médio de $k_{c}$ para o ciclo ativo, hajaja visto a demanda de àgua ser crescente com o desenvolvimento da cultura até a sua floração e frutificação (BLANEY e CRIDDLE, 1962 ; AMARO e CAVALCANTE (1981).

4.1.4. Precipitação, armazenamento de ägua e produção de massa verde

Pela anāilse dos dados da Figura 5.2 a entre duas amostragens efetuadas para determinação da massa ver- 
de, verifica-se que a menor produção foi a do espaçamento $1,70 \mathrm{~m}$, o que está coerente, devido ao menor número de plantas em relação aos demais espaçamentos, apesar do solo exibir maiores lâminas armazenadas, exceto a partir de junho, com respeito aos demais espaçamentos $(1,10$ e $1,40 \mathrm{~m})$, observa-se nitido au mento do segundo $(1,40 \mathrm{~m})$, comparado ao primeiro que dentre os outros, possuía uma maior população de plantas, muito embo ra o solo para este espaçamento $(1,10 \mathrm{~m})$ apresentasse valores de armazenamento de ägua.

o segundo ciclo da cultura, representado na Fi gura 5.2b, demonstra que a produção de massa verde obedeceu à seguinte ordem: $1,10 \mathrm{~m}>1,70 \mathrm{~m}>1,40 \mathrm{~m}$, no período de 09 de outubro de 1981 a 13 de novembro de 1981 , e no tocante a armazenamento (Figura 5.1b), no mesmo período, a tendência desse parâmetrofoi basicamente a mesma, apresentando altos valo res de água armazenada. O comportamento da produção de massa, a partir dessa data, definiu-se da seguinte maneira: 1,40m $>$ $1,10 \mathrm{~m}>1,70 \mathrm{~m}$, de modo similar como foi verificado para o mesmo parâmetro já discutido para o primeiro ciclo. Pelo exposto, as Figuras $5.1 \mathrm{~b}$ e $5.2 \mathrm{~b}$ evidenciam que, quanto mais at vo e concentrado o sistema radicular de determinada cultura, maior serā o consumo de água, donde observa-se que quan maior a densidade das plantas por metro quadrado, também maior será o consumo de àgua, como evidenciado pelos espaçamentos 
$1,10 \mathrm{~m}, 1,40 \mathrm{~m}$ e $1,70 \mathrm{~m}$, apesar da ordem de produção de massave de obtida não ser rigorosamente inversa ao volume de água armazenado pelo solo.

Para os dois ciclos da cultura, o espaçamento, $1,40 \mathrm{~m}$, demonstrou ser mais produtivo ( $t / h a)$ em relação aos demais, isto devido, provavelmente as melhores condições oferecidas por esse tratamento quanto as intërações das relações solo-àgua-planta.

\subsubsection{Produção de massa verde em relação à evapotranspiração atual ou real}

Os dados de produção de massa verde (t/ha), re lativos aos dois ciclos da cultura, nos diversos intervalos representados na Tabela 4 e Figura 6, evidenciam que a maior produção de massa verde foi a do espaçamento $1,40 \mathrm{~m}$, e as menores produções obtidas pelos espaçamentos de $1,70 \mathrm{~m}$ e $1,10 \mathrm{~m}$. Para as densidades estudadas de plantio, o menor poder de conversão correspondeu ao espaçamento $1,70 \mathrm{~m}$.

A adubação de $\mathrm{N}-\mathrm{P}-\mathrm{K}$ não serve para comparar dạ dos de produção, uma vez que foram aplicados 70 gramas por me tro linear, indistintamente às densidades de plantio. Ainda da Tabela 4, conclui-se que a cultura da cana-de-açúcar exige uma demanda crescente de àgua em seus distintos intervalos de 
crescimento, apresentando um consumo médio diário da ordem de $1,37 \mathrm{~mm} / \mathrm{dia}$ para o primeiro ciclo e de $2,83 \mathrm{~mm} / \mathrm{dia}$ relativo ao segundo ciclo. 


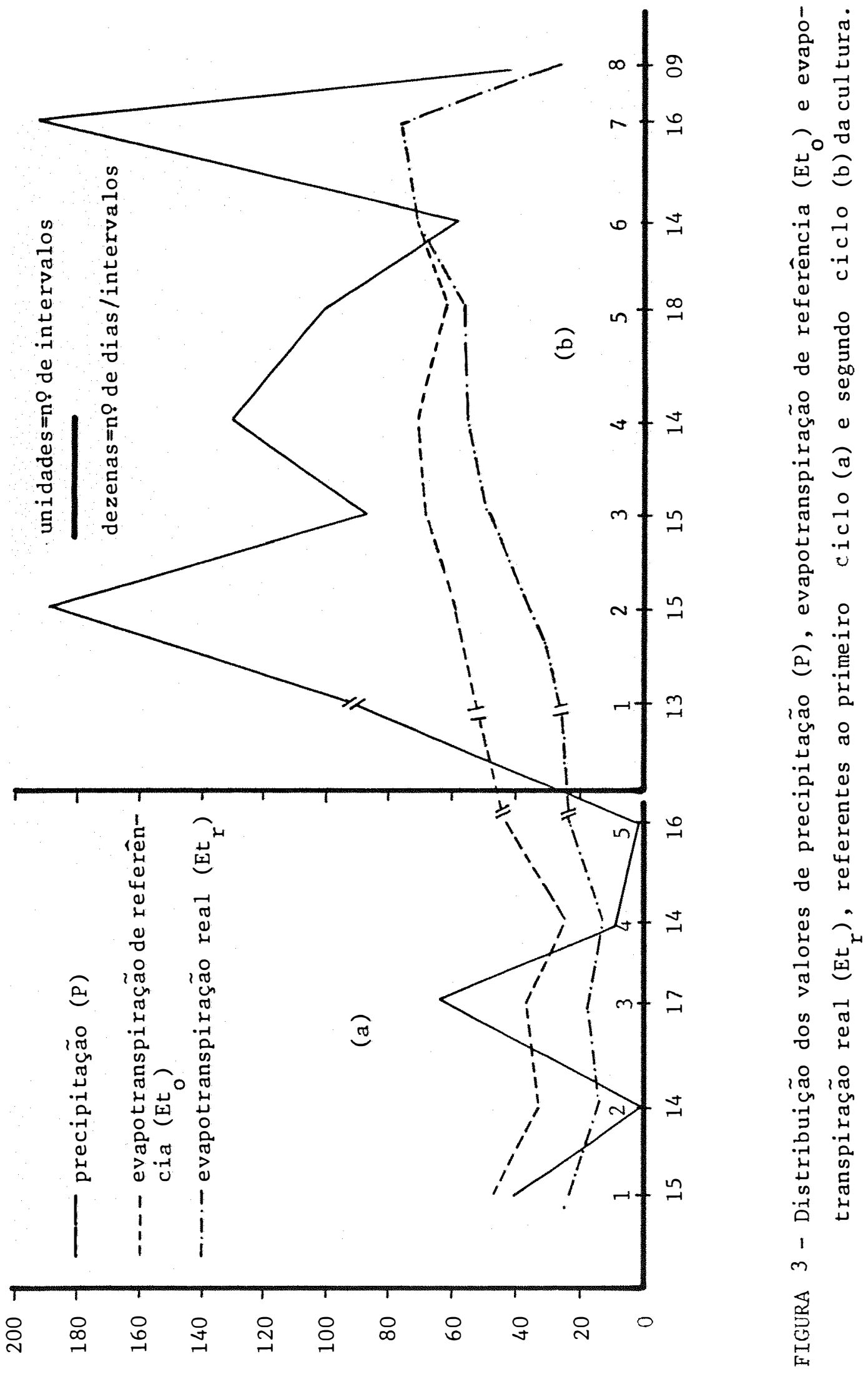




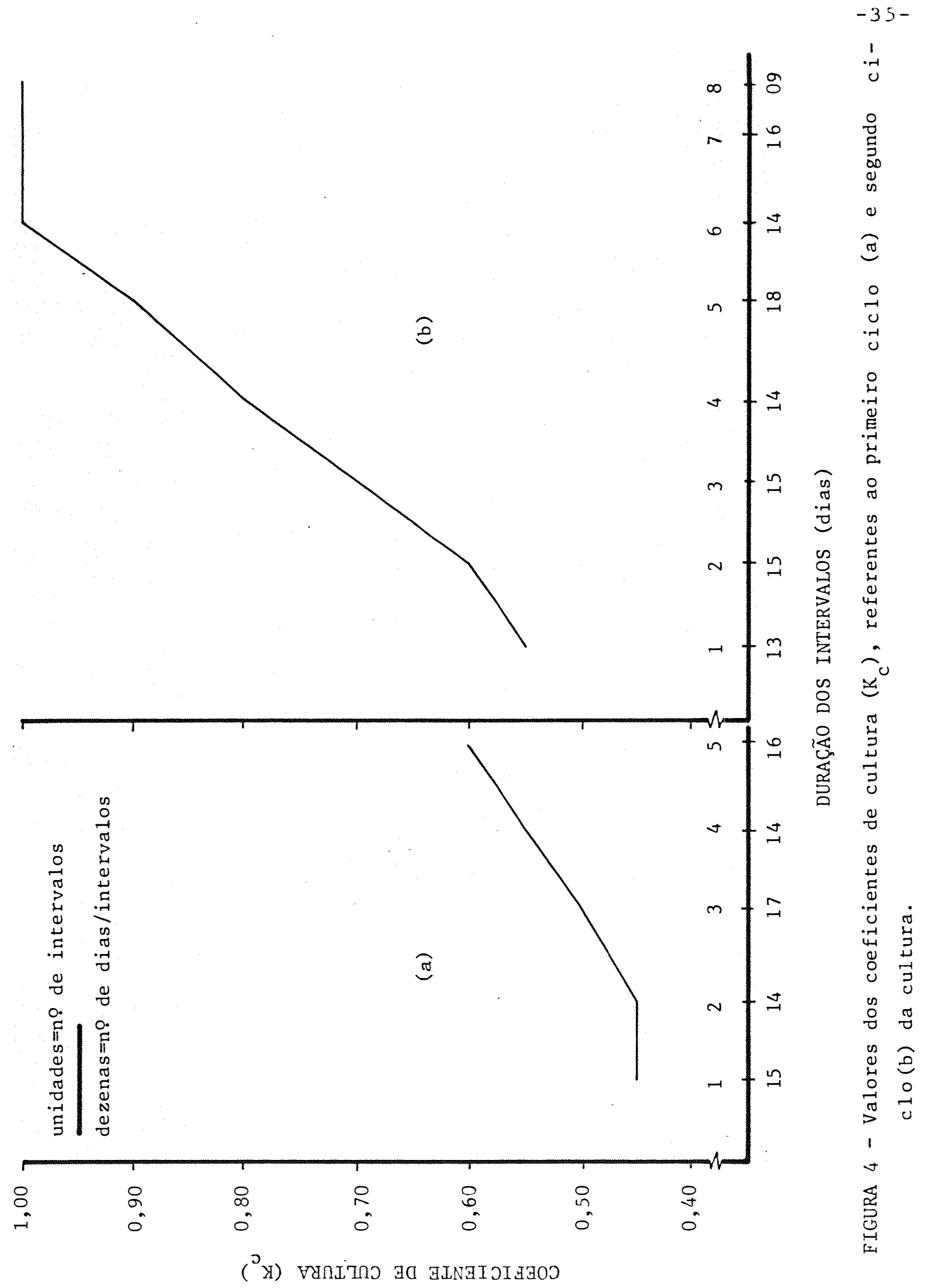


PRECIPITACCÃO D I RRIA (mm)

PRODUÇÃO DE MASSA VERDE ( $t / h a)$

$-36-$

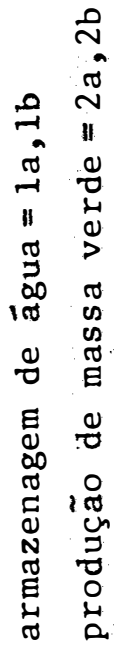

$8 \stackrel{n}{n}$ in $\approx$
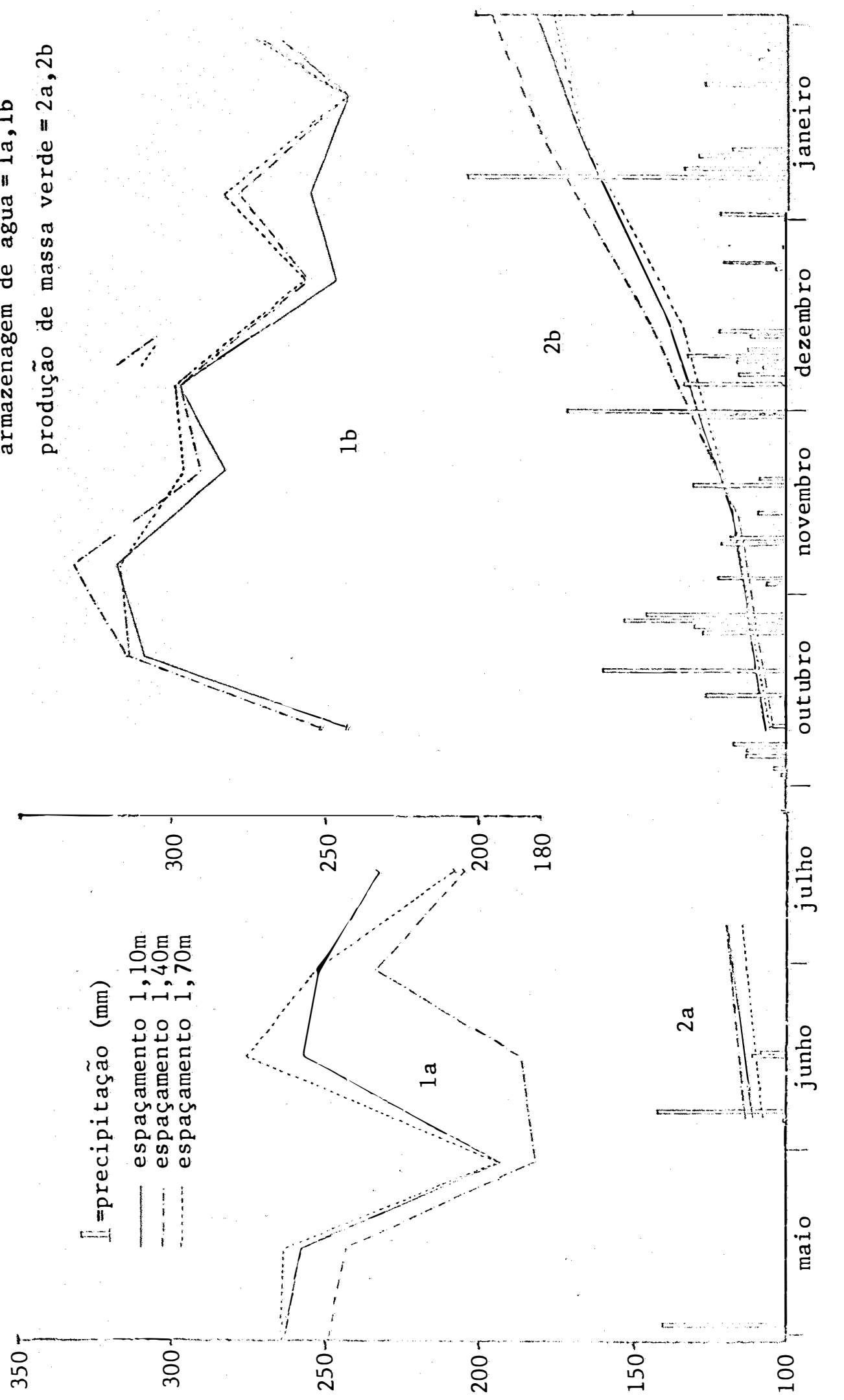

통 Ð

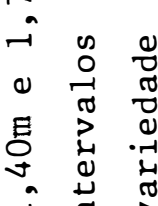

$\rightarrow$.

है ल के

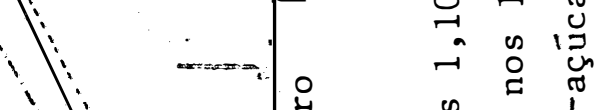

ล

1

i
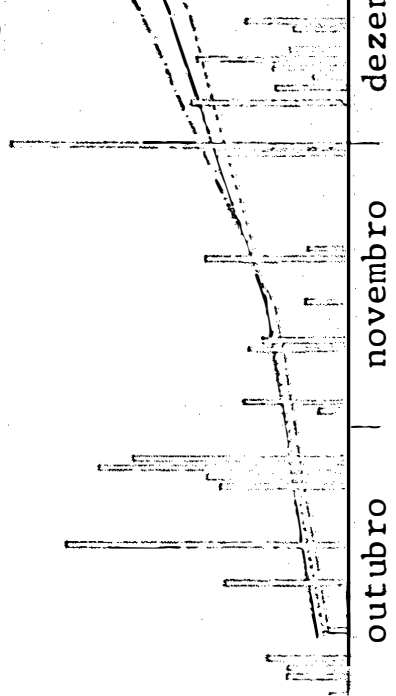

$\underset{1}{\infty}$

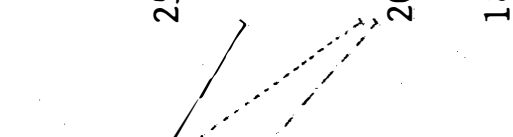

(um) OIYYIA OINGWVNGZVWCY 


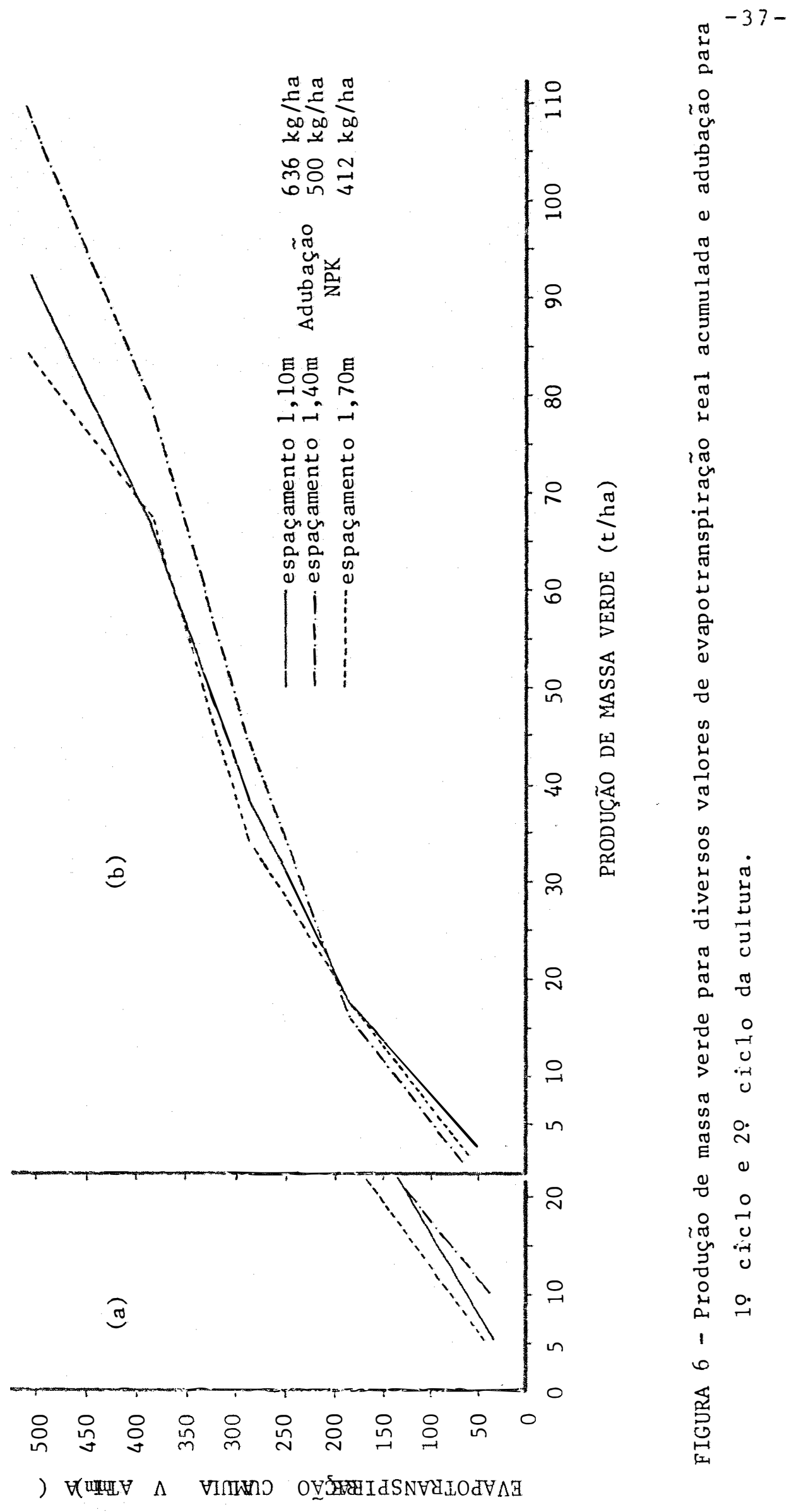




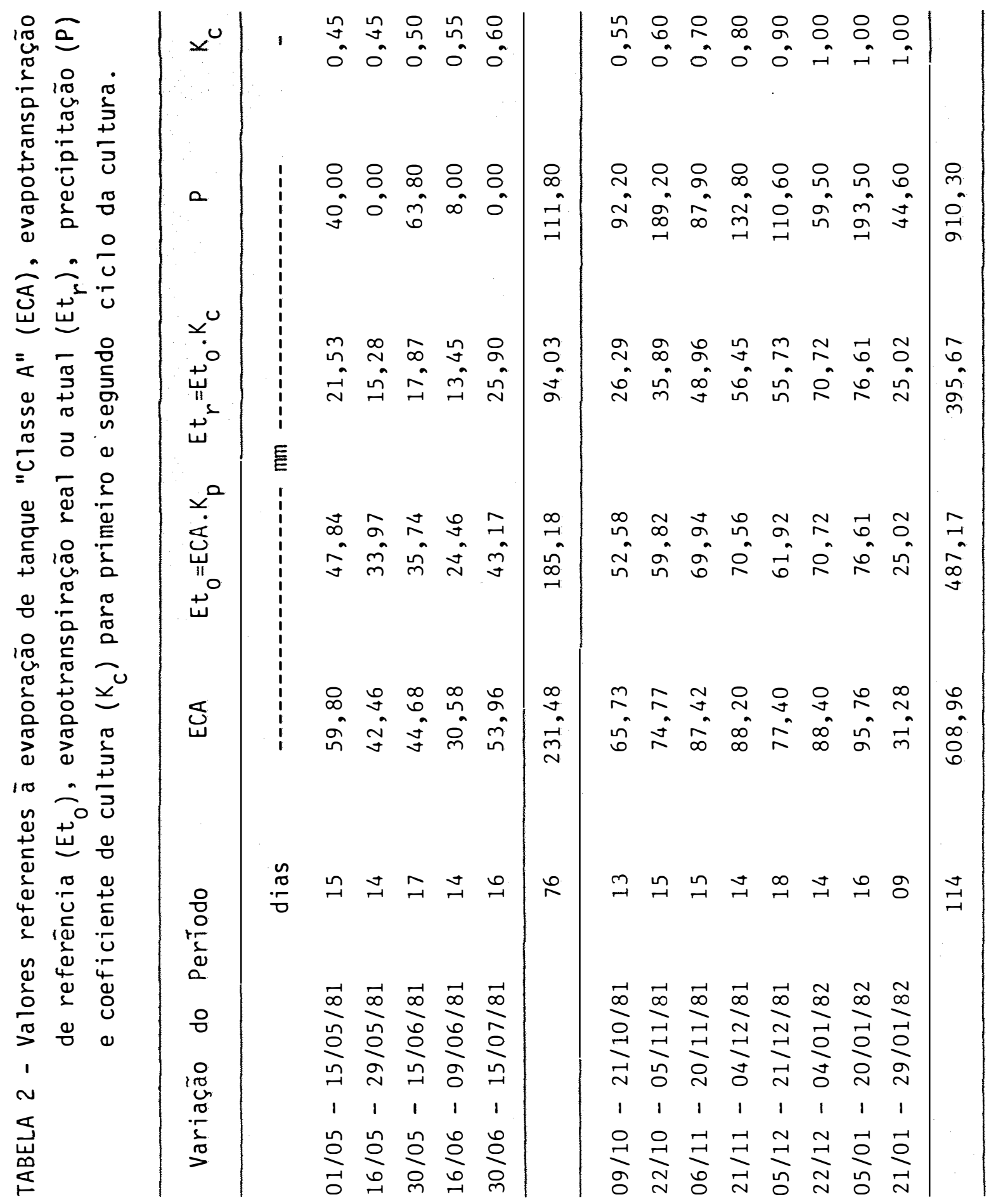




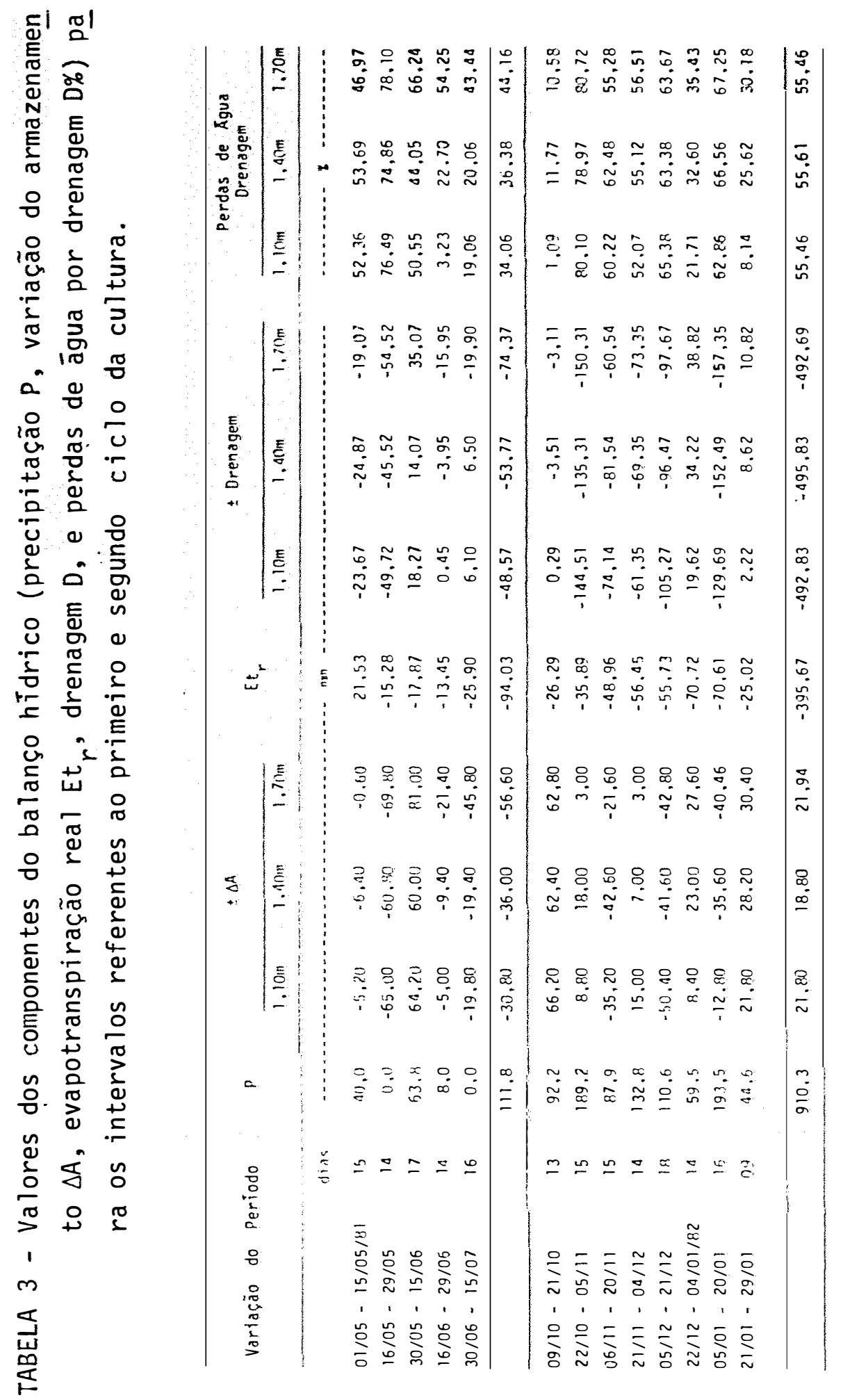




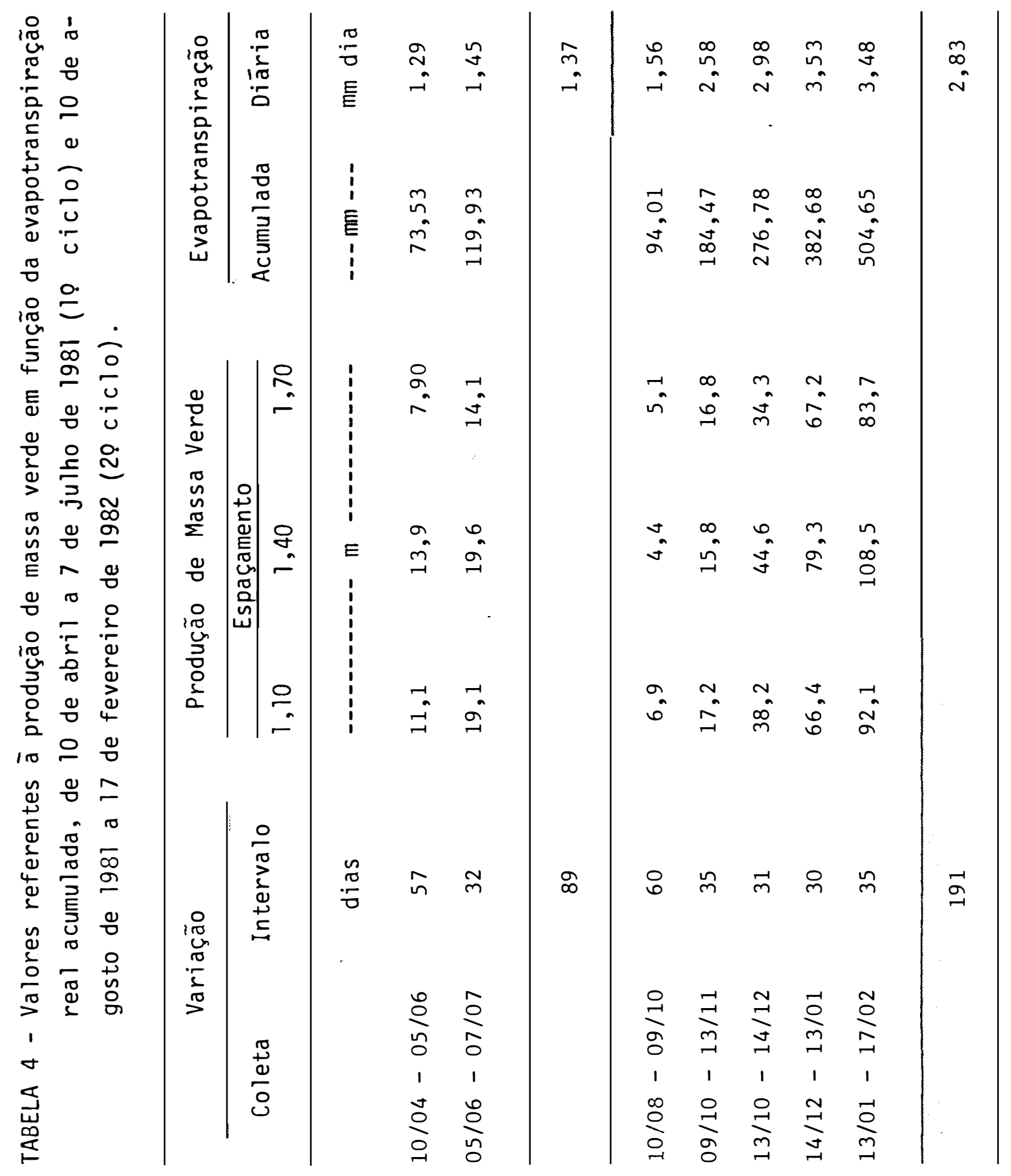




\section{CONCLUSÖES}

0 presente estudo permitiu as seguintes conclu sões:

As perdas por drenagem em função dos espaçamen tos foram mais heterogêneos no período de menor precipitação, ou seja, de maio a julho de 1981, apesar de maiores perdas no período chuvoso de outubro de 1981 a janeiro de 1982.

As perdas por drenagem para o segundo ciclo da cultura, independeram dos espaçamentos estudados e ocorreram quando a armazenagem de ägua no perfil do solo apresentava va lores mais elevados.

A maior produção de massa verde de cana-de-açū car, variedade SP 70-1143 para qualquer período considerado, foi referente ao espaçamento de $1,40 \mathrm{~m}$. 
A produção de massa verde em relação aos espaçamentos em um mesmo valor de evapotranspiração real, foi su perior para o de 1,40 m entre linhas de plantio. 


\section{LITERATURA CITADA}

AMARO, L.M. e L.F. CAVALCANTE, 1981. Uso consuntivo de um solo Litólico com algodão herbáceo, feijão macassar e milho: Anais do Curso de Pós-Graduação em Manejo e Conservação do Solo, CCA/Universidade da Paraíba.

BARRADA, Y., 1971. Water balance studies. In: Water use semi nar. Damascus. Roma, FAO, p. 90-96 (Irrigation and Draina ge Paper, no 13 .

BARROS FERRAZ, E.S., 1968. Determinação da evapotranspiração pela moderação de neutrons. Piracicaba, ESALQ/USP, 48 p. (Tese de Doutoramento).

BLACK, T.A.; W.R. GARDNER e G.W. THURTELL, 1969. The prediction of evaporation, drainage and soil water storage for a bare soil. Soil Sci. Soc. Am. Proc., 33: 655-660.

BLACK, T.A.; W.R. GARDNER e C.B. TANNER, 1970. Water storage and drainage under a row on a sand soil. Agron. J., 62: $48-51$ 
BLANEY, H.F. e W.D. CRIDDLE, 1962. Determining consuptive use and irrigation water requirements. Technical Bulletin, no 1275. Agricultural Research Service, U.S. Departament of Agriculture.

BRUNINI, O.; F. GROHMANN e J.M. SANTOS, 1981. Balanço hỉdrico em condições de campo para dois cultivares de arroz sob duas densidades de plantio. R. bras. Ci. Solo, 5: 1-6.

CASTRO, P.T., 1979. Evapotranspiração atual e potencial de uma cultura de milho (Zeamays, L.). Piracicaba, ESALQ/USP. 61 p. (Dissertação de Mestrado).

COPERSUCAR, 1982. I Seminārio de tecnologia. Piracicaba, SP. $322 \mathrm{p}$.

CRUCIANI, D.E., 1972. Balanço hídrico em solo cultivado com cana-de-açúcar. Utilização do método da moderação de neutrons. Piracicaba, CENA, 35 p. (Boletim Cintífico, no6).

DAIAN, J.F. e G. VACHAUD, 1972. Methode d'evaluation du Bilan Hydrique in situ a partir de la mesure des teneures en eau et das succions. In: IAEA. Proceedings of the sympo sium on Isotopes and Radiation in Soil-plant Relationships Including Forestry. Viena, p. 649.

DARCY, H., 1856. Les fontaines publiques de la Ville de Dijon. Paris, Victor Dalmont. 592 p. 
DEMATTE, J.L.I., 1971. Levantamento detalhado dos solos da Es tação Experimental da Copersucar de Piracicaba. Piracicaba, ESALQ/USP. $52 \mathrm{p}$.

DOOREMBOS, J. e W.0. PRUITT, 1975. Crop. water requirements. Roma, FAO, 179 p. (Irrigation and Drainage Paper, n8 24).

DOWNEY, L.A., 1972. Water-yelds relation for nonforage crops. J. Irr. Drain, 98: 107-115.

GIESEL, W.; S. LORCH e M. RENGER, 1970. Water-flow calculations by means of gamma absorption and tensiometer field me asurements in the unsaturated soil profile. IAEA, Isotope Hydrology. Vienna, p. 663-672.

HARGREAVES, G.H., 1974. Potential evapotranspiration and irri gation requirements for Northeast Brazil. Salt Lake City, Utah State University/USAID. 55 p..

IAPAR, 1977. Relatório especial de pesquisa sobre manejo e conservação do solo. 52 p.

JENSEN, M.E.; D.C. ROBB e E. FRAZOI, 1970. Scheduling irriga tion using climate-crop-soil data. J. Irrig. Drain., 96 : $25-38$

KOHLER, M.A., 1957. Meteorological aspects of evaporation phe nomena. Trans. Int. Assoc. Sci. Hydrology. Toronto, General Assembly. 
LEITE, A.C., 1978. Aplicação do método do balanço hỉdrico de energia e de métodos aerodinâmicos de Thorthwaite e Holzman na estimativa da evapotranspiração em cultura de feijão (Phaseolus vulgaris, L.). Piracicaba, ESALQ/USP. 65p., (Dissertação de Mestrado). .

LUCHIARI JUNIOR, A., 1978. Determinação do coeficiente de cu tura $\left(K_{c}\right)$ para feijão (Phaseolus vulgaris, L.) pelo método do balanço hỉdrico. Piracicaba, ESALQ/USP, 59p. (Dissertação de Mestrado).

MATHERNE, R.J., 1971. Influence of interrow spacing and planting rate on stalk population and yield of cane in Louisiana. U.S.D.A., Proc. of the XIV Congress of the Intern. Soc. Sugarcane Tecnol.

MILlAR, A.E. e E.N. CHOUdHURY, 1977. Movimento de água em oxi sol irrigado. Centro de Pesquisas Agropecuárias do Trópico Semi-Ārido. Petrolina, PE, p.193-197.

NIXON, P.R. e G.P. LAWLESS, 1960. Translocation of moisture with time in unsaturated soil profiles.J.Geoph. Res. 65: $655-660$.

PAIVA JUNIOR, P., 1980. Balanço hỉdrico em uma cultura de tomate (Lycopersicum esculentum, Mil1), irrigada através de cápsulas porosas de barro. Piracicaba, ESALQ/USP, 105 p. (Dissertação de Mestrado). 
PARANHOS, S.B., 1972. Espaçamento e densidade de plantio em cana-de-açūcar. Piracicaba, ESALQ/USP, 109p. (Tese de Doutoramento).

PEREIRA, A.R.; E.S.B. FERRAZ; K. REICHARDT e P.L. LIBARDI, 1974. Estimativa da evapotranspiração e da drenagem profunda em cafezais cultivados em solos podzolizados Lins e Marília. Piracicaba, CENA, BC-014.

REICHARDT, K., 1974. Determinação da condutividade hidrāulica em condições de campo para a estimativa da drenagem profunda em balanço hỉdrico. Piracicaba, CENA, BC-015.

REICHARDT, K., 1975. Processos de Transferência no Sistema So Zo-PZanta-Atmosfera. São Paulo, Fundação Cargill; Piraci caba, CENA. 286 p.

REICHARDT, K.;F.GROHMANN; P.L. LIBARDI e S.V. QUEIROZ, 1976 . Spatial variability of physical properties of a tropical soil. Piracicaba, CENA, 27p. (Boletim Técnico, no 4).

REICHARDT, K.; P.L. LIBARDI; L.C.U. SAUNDER e Z.A. CADIMA, 1979. Dinâmica da àgua em solo cultivado commilho. R. bras. Ci. Solo, 3: 1-5.

ROSE, C.W.; W.R. STERN E J.E. DRUMOND, 1965. Determination of hydraulic conductivity as a function of depth and water content for soil in situ. Aust. J. Soil Res., 3: 1-9. 
ROSE, C.W., 1966. Agricultural physics. Oxford, Pergamon Press. 230 p.

ROSE, C.W. e W.R. STERN, 1967. Determination of withdrawal of water from soil by crop roots as function of depth and time. Aust. J. Soil Res., 5: 11-19.

SINGER, $\dot{P}$. e M.B. RUSSEL, 1979. Water balance and profile los patterns of on alfissol. Agron. J., 71(6): 963-966.

STAMERS, W.N.; O.C. IGWE e H.R. WASTELEY, 1973. Calculation of evapotranspiration from measurements of soil water and soil water characteristic. Canadian Agric. Eng., 15: 2-5.

TAMES, C., 1962. Considerations on balance in dry climates and different types of soil. In: Plant-water relationship in arid and semi-arid conditions. (Proceeding of the Ma drid Symposium, UNESCO, p-57-61.

TANNER, C.B., 1968. Evaporation of water from plants and soil. In: KOLOWSKI, T.T., Ed. Water deficits and plant growth. New York, Academic Press, p.74-106.

VILla NOVA, N.A. e J.C. OMETTO, 1977. Instruções para utilizą ção do tanque "Classe A" em estimativas de evapotranspiração potencial, real e frequência de irrigação. Piracicaba, ESALQ/USP, Departamento de Física e Meteorologia (Publicação Especial), $15 \mathrm{p}$.

W.M.O., 1966. Measurement and estimation of evaporation and evapotranspiration. Geneva, $121 \mathrm{p}$. (Technical Note, no 83). 